\title{
Forecasting tourism-generated employment: the case of Denmark
}

\author{
S TEPHEN F. W ITT \\ School of Management, University of Surrey, Guildford, Surrey GU2 7XH, UK. Tel: \\ + 441483 876323.Fax: + 441483 876301.E-mail: j.nash@surrey.ac.uk. \\ H AIYAN SONG \\ School of Management, University of Surrey, Guildford, Surrey GU2 7XH, UK. Tel: \\ + 441483 876323. Fax: + 441483 876301. E-mail: h.song@surrey.ac.uk. \\ S TEPHEN W ANHILL \\ International Centre for Tourism and Hospitality Research, Bournemouth University, Talbot \\ Campus, Fern Barrow, Poole, BH12 5BB, UK. Tel: + 441202 595384. Fax: + 44 \\ 1202 515707.E-mail: swanbill@bournemouth.ac.uk.
}

\begin{abstract}
The empirical results from a forecasting competition show that the unrestricted vector autoregressive model is likely to generate the most accurate forecasts of international tourist expenditure in Denmark. This model is therefore estimated (using data for 1969-99) and is used to generate tourism expenditure forecasts for Denmark to 2010. The employment requirements (direct, indirect and induced) associated with these expenditure forecasts are then estimated using an input-output model. The forecasts of employment demands are shown across all industrial sectors, and linked to qualifications data in respect of the labour force. The major impacts of foreign tourist expenditure on employment in Denmark occur in the retail, hotel and restaurant sectors. Foreign tourist expenditure is also significantly associated with graduate employment.
\end{abstract}

Keywords: tourist expenditure forecasts; tourism employment forecasts; vector autoregressive model

Tourism demand forecasts are an essential requirement for tourism planning and decision making at both national and firm levels. It is important that accurate forecasts are produced so that planning and decision making are based on sound information.

Many tourism forecasting studies have been published over the past thirty

The authors gratefully acknowledge the support of the Danish Social Science Foundation for this study through the Danish Centre for Tourism Research. 
years. These have generally been concerned with forecasting tourist visits, tourist expenditure or tourist nights (for a review of the tourism forecasting literature, see Witt and Witt, 1995 - for more recent studies see DuPreez and Witt, 2003; Kulendran and Witt, 2001, 2003; Song et al, 2000; Song and Witt, 2000, 2004; Song et al, 2003; Turner and Witt, 2001). Many other studies have examined tourism impacts (for a seminal review see Fletcher, 1989, and for more recent studies see Frechtling and Horvath, 1999; Zhang, 2002; Zhou et al, 1997).

However, in only a few cases (Wanhill, 1992) have attempts been made to combine tourism forecasting and tourism impact analysis and examine the manpower requirements associated with tourism demand forecasts, other than at a very aggregate level by applying ratios to visitor projections in government tourism strategies. Yet such forecasts are crucial to ensure that adequate numbers of appropriately qualified people are available in the workforce to meet the demands of tourists.

The purpose of this paper is to use empirical results from a forecasting competition involving data on inbound tourism to Denmark to select the forecasting method that is likely to generate the most accurate forecasts of international tourist expenditure, and to use this forecasting method to generate forecasts of international tourist expenditure to 2010. The corresponding forecasts of tourism employment are then derived. The impacts of this international tourism generated employment are examined, both by industry and by qualification.

\section{Previous study}

Witt et al (2003) have examined the ability of various econometric and timeseries models to generate accurate out-of-sample forecasts of inbound tourism to Denmark. Six major origin countries are examined: Germany, the Netherlands, Norway, Sweden, the UK and the USA. The models are estimated using annual data for 1969-93, and the estimated models are used to generate forecasts for 1994-99. Forecasting performance is assessed in terms of mean absolute percentage error (MAPE), which gives equal weight to all percentage errors, and root mean square percentage error (RMSPE), which gives more weight to avoiding large percentage errors (for a discussion of these error measures, see Witt and Witt, 1992).

Six econometric models are specified to explain tourism demand. These are special cases of a general autoregressive distributed lag model (ADLM), and the initial ADLM takes the form:

$$
\begin{aligned}
\ln Q_{i t}= & \alpha+\phi \ln Q_{i t-1}+\eta_{1} \ln Y_{i t}+\eta_{2} \ln Y_{i t-1}+\eta_{3} \ln P_{i t}+\eta_{4} \ln P_{i t-1} \\
& +\eta_{5} \ln P_{i s t}+\eta_{6} \ln P_{i s t-1}+\eta_{7} T+\text { dummies }+u_{i t}
\end{aligned}
$$

where $Q_{i t}$ is the quantity of tourism consumed per capita measured by the expenditure-weighted number of nights spent by tourists from country $i$ in Denmark (the weights reflect the different daily spending for tourists in different accommodation types in 1996) divided by the population of country $i(1980=100) ; Y_{i t}$ is real private consumption expenditure per capita in country $i(1980=100) ; P_{i t}$ represents the real cost of living for tourists in Denmark, and 
is measured by the Denmark CPI relative to the CPI in country $i$, adjusted by the exchange rate in order to transform the price variable into origin country currency; $P_{\text {ist }}$ represents tourism prices in substitute destinations and is measured by the tourists' cost of living in Denmark relative to a weighted average calculated for a set of alternative destinations for origin country $i$; $T$ is a time trend; and the dummy variables comprise two oil crisis dummies DOIL1 and DOIL2 (DOIL1 $=1$ in 1974-75, =0 otherwise; DOIL2 $=1$ in 1979, $=0$ otherwise), a Gulf War dummy (DGULF=1 in 1990-91, =0 otherwise), a dummy for German unification (applies to Germany model only) (DGERM=1 in 1991, $=0$ otherwise), and a dummy for Chernobyl/the US bombing of Libya (DCHERNO $=1$ in 1986, $=0$ otherwise). $u$ is an error term and $\alpha, \phi, \eta_{1}, \eta_{2}, \ldots$, $\eta_{7}$ are unknown parameters. A travel cost variable, measured by the real economy airfare from the USA to Denmark, was also originally included in the USA model (as travel cost was thought to be potentially important for longhaul travel), but it was found to be insignificant in the empirical analysis, so this variable is omitted from Equation (1). For a full justification and discussion (a) of the form of the dependent variable see Jensen (1998), and (b) of this standard set of explanatory variables included in tourism demand models see Witt and Witt (1992, 1995).

The data on nights spent in Denmark by tourists from the various origin countries were obtained from Statistics Denmark's Annual Statistical Yearbook. The data cover different categories of accommodation, which represent different daily expenditure patterns by tourists. For each origin country, the number of nights spent in the various accommodation categories is weighted by daily expenditure (obtained from a survey conducted by the Danish Tourist Board in 1996) to give the measure of tourism demand. Data on private consumption expenditure, consumer price indices and exchange rates were obtained from the OECD's Economic Outlook. The weights used in calculating tourist prices in substitute destinations reflect the distribution of tourist nights in competing destination countries for a given origin, and were obtained from the World Tourism Organization's Yearbook of Tourism Statistics and the OECD's Tourism Policy and International Tourism.

By imposing certain restrictions on the parameters in Equation (1) a number of specific models may be derived, and the six econometric models specified by Witt et al (2003) are: a static (cointegration) model; two error correction models, one estimated using the Wickens and Breusch (1988) procedure (WB) and another estimated using the Johansen (1988) maximum likelihood method (JML); a reduced ADLM; a time varying parameter (TVP) model; and an unrestricted vector autoregressive (VAR) model. The two alternative error correction models (ECMs) are investigated as the WB approach is particularly appropriate for the small sample size, whereas the JML approach allows for the possibility of more than one cointegrating relationship (which is the case for some origin countries). The time varying parameter model allows demand elasticities to change over time, and so is highly adaptable in dealing with structural change in econometric models. The static model, ECMs, reduced ADLM and TVP model assume that the explanatory variables in the tourism demand function are exogenous. If this assumption is invalid, a VAR model may be more appropriate. Two time-series models are also included in the study as benchmark comparators: an ARIMA model based on the Box-Jenkins procedure 
Table 1. Error magnitude forecasting accuracy.

\begin{tabular}{lrrrrrr}
\hline & \multicolumn{2}{c}{1 year ahead } & \multicolumn{2}{c}{ 2 years ahead } & \multicolumn{2}{c}{3 years ahead } \\
Model & MAPE & RMSPE & MAPE & RMSPE & MAPE & RMSPE \\
& & & & & & \\
Static & $8.86(5)$ & $17.06(6)$ & $10.30(7)$ & $24.60(7)$ & $13.89(5)$ & $30.38(7)$ \\
WB & $9.14(6)$ & $15.67(5)$ & $10.05(5)$ & $22.42(6)$ & $14.52(7)$ & $27.53(6)$ \\
JML & $12.89(8)$ & $23.45(8)$ & $82.54(8)$ & $91.57(8)$ & $20.51(8)$ & $37.97(8)$ \\
Reduced ADLM & $6.26(1)$ & $11.10(3)$ & $7.05(2)$ & $16.06(4)$ & $9.47(2)$ & $19.42(4)$ \\
TVP & $7.21(2)$ & $10.71(2)$ & $10.07(6)$ & $16.81(5)$ & $14.32(6)$ & $22.22(5)$ \\
VAR & $10.33(7)$ & $19.23(7)$ & $6.79(1)$ & $11.49(1)$ & $7.92(1)$ & $12.93(1)$ \\
ARIMA & $8.21(4)$ & $10.21(1)$ & $9.62(4)$ & $13.78(2)$ & $12.99(4)$ & $16.57(2)$ \\
No change & $7.74(3)$ & $12.70(4)$ & $7.60(3)$ & $15.37(3)$ & $10.14(3)$ & $19.19(3)$ \\
\hline
\end{tabular}

Note: Values in parentheses are rankings.

Source: Witt et al (2003).

(Box and Jenkins, 1976); and a simple naïve no-change (or random walk) model. Full details of the model specifications, together with the empirical results for model estimation, are given in an earlier study by Song et al (2003).

The models are estimated using data from 1969 to 1993, and the estimated models are used to generate one-, two- and three-years-ahead ex post forecasts over the period 1994-99. Six one-year-ahead, five two-years-ahead and four three-years-ahead forecasts are obtained for each model for each origin country. As the objective is to compare the forecasting performance of the various models, the forecasting evaluation is model specific rather than origin-country specific.

The empirical results are presented in Table 1. For one-year-ahead forecasts, the reduced ADLM is ranked first according to the MAPE criterion and third in terms of RMSPE, whereas the ARIMA model is ranked first according to the RMSPE criterion and fourth in terms of MAPE. The TVP model generates the second most accurate forecasts in both cases. For two-years-ahead and threeyears-ahead forecasts the VAR model is the clear winner, ranking first in terms of both accuracy measures. This is followed by the reduced ADLM in the case of MAPE and ARIMA model in the case of RMSPE.

\section{Tourism expenditure forecasts}

As the objective is to obtain long-term forecasts of international tourism demand, the VAR model is selected for forecast generation. The superior performance of the VAR model implies that the distinction between endogenous and exogenous variables in tourism demand forecasting models is not clear, and it is important to take this into account when generating longer-term forecasts.

The VAR models employed by Witt et al (2003) are re-estimated with data for 1969-99 and are used to calculate forecasts of foreign tourist expenditure in Denmark to 2010. There is no need to forecast the explanatory variables separately. The VAR model treats all variables as endogenous and relates each variable to the lagged values of the forecast and explanatory variables. These 
Table 2. Forecasts of foreign tourist expenditure in Denmark (DKK million, 1999 prices).

\begin{tabular}{lrrrrrr}
\hline Origin country & 1999 & 2000 & 2005 & 2010 & $\begin{array}{c}\text { AAGR(\%) } \\
\text { 2000-05 }\end{array}$ & $\begin{array}{c}\text { AAGR(\%) } \\
\text { 2005-10 }\end{array}$ \\
Germany & 11,129 & 11,787 & 14,530 & 17,316 & 4.3 & 3.6 \\
Netherlands & 393 & 409 & 452 & 501 & 2.0 & 2.1 \\
Norway & 3,410 & 3,530 & 4,025 & 4,624 & 2.7 & 2.8 \\
Sweden & 6,973 & 6,896 & 8,701 & 10,244 & 4.8 & 3.3 \\
UK & 494 & 503 & 519 & 539 & 0.6 & 0.8 \\
USA & 554 & 440 & 439 & 405 & 0.0 & -1.6 \\
Others & 4,936 & 5,068 & 6,165 & 7,232 & 4.0 & 3.2 \\
Total & 27,889 & 28,633 & 34,831 & 40,861 & 4.0 & 3.2 \\
\hline
\end{tabular}

Note: 1999 figures are actual values. AAGR denotes average annual growth rate.

forecasts are shown in Table 2, in which the 1999 data are actual values. The category 'others' is calculated as a residual and is assumed to grow in line with the overall trend.

Markedly different growth rates for tourist expenditure are forecast for the various markets. The highest average annual growth rates are recorded for Germany and Sweden (4\%), followed by Norway (3\%), the Netherlands (2\%), the UK $(1 \%)$ and the USA $(-1 \%)$. Germany and Sweden dominate the Danish inbound tourism market and are forecast to account for $67 \%$ of inbound international tourist expenditure by 2010 .

\section{Tourism employment forecasts}

Assessing the employment requirements associated with the tourism demand forecasts is a strategic matter involving long-term considerations of human resource development that are important to both governments and the private sector. Tourism is not an industry defined by any standard industrial classification. It is demand-led; its influence pervades many industrial sectors of the economy and so it is impossible to measure the employment created through an examination of the supply side or tourism-related sectors, which in the case of Danish national statistics are listed as 'Hotels', 'Restaurants' and 'Recreation and cultural activities' (Zhang, 2002). For example, a good deal of employment in the restaurant sector has little to do with tourism, as many such businesses exist just to serve local demand. Too often, for lack of data, industry projections of employment are based on forecasts of visitor numbers or the expected development of hotel rooms (Wanhill, 1992), but these fail to examine linkages and feedback effects, thus giving only a partial answer. The use of an integrated model in the form of an input-output table yields a much more complete scenario, linking the demands of the tourist to the economy as a whole.

The simulation exercise to model employment was undertaken using the output of a Keynesian macroeconomic system with an interregional inputoutput model of Denmark as its core. The method is, in principle, a standard one of interregional input-output modelling, as reviewed in Oosterhaven and 
Van der Knijf (1987). The model covers the fourteen counties of Denmark and is based at the AKF Institute of Local Government Studies in Copenhagen. Over time it has gone through several redevelopment phases, and the name LINE has been given to the latest version of the model in which the accounting structure is based on the SAM framework (Madsen et al, 2001).

The model is in general use for economic planning purposes (Eriksen and Ahmt, 1999), for it provides estimates of a large number of key regional economic variables including:

- gross output by sector and by place of production;

- GDP at factor cost by sector and by place of production;

- employment by sector and by place of production;

- employment and unemployment by sector and by place of residence;

- employment by qualification group and by place of residence;

- disposable income by type of household and by place of residence;

- central government taxes and different region-based taxes by place of residence;

- transfer incomes by qualification group or by household and by place of residence;

- private consumption by component and by place of demand;

- interregional exports and imports by commodity;

- retailing and wholesaling margins by commodity; and

- VAT and commodity tax by commodity.

More recently it has been used to simulate tourism impacts, overall (Zhang, 2002) and with regard to taxation (Jensen and Wanhill, 2002). To maintain consistency, the forecasts given in Tables 3 and 4 follow Zhang's work, in which the appropriate employment multipliers are derived by running the model with tourism consumption set to zero.

Table 3 shows five-yearly forecasts of employment demands generated by foreign tourists across all industrial sectors, measured in full-time equivalents (FTEs). The implied assumption is that there is no major switching in the pattern of foreign tourist expenditure between categories that would alter impacts between sectors. The most significant impacts can be found in 'Retail', 'Hotels' and 'Restaurants', whereas the effects on 'Recreation and cultural activities' are relatively small. The latter finding can be explained by the fact that this sector is largely supply-determined in Denmark as a range of public merit goods for the benefit of the domestic population that are either free or heavily subsidized at the point of use. Thus foreign tourist expenditure has little influence on overall provision.

Table 4 links employment demands with qualifications data in respect of the Danish labour force, although it is important to note that the connection between education and the skills base of the labour force is somewhat loosely geared because skills are produced in formal and informal ways, and the education system has wider objectives than employment for national prosperity. Simply put, education is for life skills whereas training, particularly when it is intimately coupled with the place of employment, can be for immediate use on the job. Vocational education and training are a means of tightening the link between education and the skills base in the labour force, and constitute an important component of Table 4, thereby speeding up the acquisition of 
Table 3. Forecasts of foreign-tourism-generated employment impacts by industry (fulltime equivalents).

\begin{tabular}{lrrrrrr}
\hline Industrial sector & 1999 & 2000 & 2005 & 2010 & $\begin{array}{r}\text { Growth, } \\
\text { 2000-05 }\end{array}$ & $\begin{array}{r}\text { Growth, } \\
\text { 2005-10 }\end{array}$ \\
& & & & & & \\
Agriculture & 1,466 & 1,505 & 1,830 & 2,147 & 326 & 317 \\
Food, beverages, tobacco & 1,432 & 1,471 & 1,789 & 2,099 & 318 & 310 \\
Construction & 399 & 410 & 499 & 585 & 89 & 86 \\
Wholesale & 2,609 & 2,678 & 3,258 & 3,822 & 580 & 564 \\
Retail & 8,723 & 8,956 & 10,894 & 12,781 & 1,939 & 1,886 \\
Hotels & 5,079 & 5,215 & 6,344 & 7,442 & 1,129 & 1,098 \\
Restaurants & 4,696 & 4,821 & 5,864 & 6,880 & 1,044 & 1,015 \\
Transport & 2,631 & 2,702 & 3,286 & 3,855 & 585 & 569 \\
Finance and insurance & 967 & 993 & 1,208 & 1,417 & 215 & 209 \\
Other private service & 2,709 & 2,782 & 3,384 & 3,970 & 602 & 586 \\
Public service & 2,618 & 2,688 & 3,270 & 3,836 & 582 & 566 \\
Recreation and & 892 & 916 & 1,115 & 1,308 & 198 & 193 \\
$\quad$ cultural activities & & & & & & \\
Other industries & 2,374 & 2,437 & 2,965 & 3,478 & 528 & 513 \\
All sectors & 36,596 & 37,572 & 45,705 & 53,618 & 8,133 & 7,913 \\
\hline
\end{tabular}

Note: 1999 figures are actual values.

Table 4. Forecasts of foreign-tourism-generated employment impacts by qualification (full-time equivalents).

\begin{tabular}{lrrrrrr}
\hline Qualification & 1999 & 2000 & 2005 & 2010 & $\begin{array}{r}\text { Growth, } \\
\text { 2000-05 }\end{array}$ & $\begin{array}{r}\text { Growth, } \\
\text { 2005-10 }\end{array}$ \\
& & & & & & 342 \\
Basic education & 1,580 & 1,623 & 1,974 & 2,316 & 351 & 706 \\
Secondary education & 3,264 & 3,351 & 4,077 & 4,783 & 725 & 2,650 \\
Vocational education & 12,258 & 12,585 & 15,309 & 17,960 & 2,724 & 286 \\
Higher vocational & 1,322 & 1,357 & 1,651 & 1,937 & 294 & 429 \\
$\quad$ education & & & & & & 441 \\
First-stage university & 1,985 & 2,038 & 2,479 & 2,908 & 254 & 247 \\
Second-stage university & 1,143 & 1,173 & 1,427 & 1,674 & 3,343 & 3,253 \\
Full-stage university & 15,044 & 15,445 & 18,788 & 22,041 & 3,943 \\
All groups & 36,596 & 37,572 & 45,705 & 53,618 & 8,133 & 7,913 \\
\hline
\end{tabular}

Note: 1999 figures are actual values.

those same skills. However, even here the curriculum has to be generalized because the output is not tied to the demands of a particular employer.

Given the slackness in the relationship between qualifications and workforce needs, the common-sense approach is to see the forecasts in Table 4 as a general guide to the interaction of the tourism industry with the education system. For example, the seasonal nature of tourism demand in Denmark corresponds well with the employment of the university student population, some of whom subsequently find themselves opportunities in those sectors most directly connected with tourism. Furthermore, given the high importance the Danish people attach to education, it is hardly surprising that the direct, indirect and 
induced effects of tourist expenditure, when taken across all industries, are likely to be significantly associated with graduate employment as shown in Table 4. Note that no allowance has been made in these forecasts for productivity improvements and wastage through retirements from the labour force. These two variables move in opposite directions and tend to cancel each other out when recruitment provision is considered, particularly in services where productivity is normally low, in the order of $0-3 \%$ (Wanhill, 1992).

\section{Summary and conclusion}

In a previous forecasting exercise, Witt et al (2003) examined the ability of various econometric and time-series models to generate accurate out-of-sample forecasts of inbound tourism to Denmark from six major origin countries. Six econometric models were considered: a static (cointegration) model; two error correction models, one particularly appropriate for small samples and the other allowing for more than one cointegrating relationship; a reduced autoregressive distributed lag model; a time varying parameter model; and an unrestricted vector autoregressive model. Two time-series models were considered: an ARIMA model and a simple naïve no-change model. The models were estimated using annual data from 1969-93 and were used to generate one-yearahead, two-years-ahead and three-years-ahead forecasts over the period 199499. The empirical results showed clearly that the most accurate forecasting method for the longer-term forecasting horizons (two and three years ahead) is the vector autoregressive model. The VAR models used in the Witt et al (2003) study have therefore been re-estimated with data for the period 196999 and used to generate forecasts of foreign tourist expenditure in Denmark to 2010 .

The employment requirements (direct, indirect and induced) associated with the forecasts of international tourism demand have been estimated using the output of a Keynesian macroeconomic system with an interregional inputoutput model of Denmark as its core. The forecasts of employment demands are shown across all industrial sectors, and are also linked to qualifications data in respect of the Danish labour force. It can be seen that the major impacts of foreign tourist expenditure on employment occur in the retail, hotel and restaurant sectors. The qualifications data show that foreign tourist expenditure is significantly associated with graduate employment.

The standard procedure in recent tourism demand forecasting studies has been to assess the forecasting performance of alternative models in terms of out-of-sample forecasting accuracy. Only rarely do studies provide forecasts into the future (as measured by the number of visits, number of nights or tourist expenditure); see, for example, Smeral and Witt, 1996; Turner and Witt, 2003. Furthermore, although many tourism impact studies have been published, it appears from an examination of the academic literature that there has been no attempt during the last decade to combine future tourism demand forecasts with tourism impact analysis to examine the workforce requirements associated with tourism demand forecasts - and yet the link to the employment requirements associated with the forecast level of tourism demand provides essential information for planners to ensure that adequate 
numbers of appropriately qualified people are available in the workforce to service the forecast level of tourism demand. This study has demonstrated, in the context of Danish inbound tourism, how an input-output model that links the demands of the tourist to the economy as a whole can be combined with forecasts of tourism demand to identify the future workforce requirements of the tourism industry.

\section{References}

Box, G. E. P., and Jenkins, G.M. (1976), Time Series Analysis: Forecasting and Control, Holden-Day, San Francisco, CA.

DuPreez, J., and Witt, S.F. (2003), 'Univariate versus multivariate time series forecasting: an application to international tourism demand', International Journal of Forecasting, Vol 19, pp 435451.

Eriksen, L., and Ahmt, T. (1999), 'Measuring and modelling the regional impact of tourism in Denmark', International Journal of Tourism Research, Vol 1, No 5, pp 313-328.

Fletcher, J. E. (1989), 'Input-output analysis and tourism impact studies', Annals of Tourism Research, Vol 16, pp 514-529.

Frechtling, D. C., and Horvath, E. (1999), 'Estimating the multiplier effects of tourism expenditures on a local economy through a regional input-output model', Journal of Travel Research, Vol 37, No 4, pp 324-332.

Jensen, T. (1998), 'Income and price elasticities by nationality for tourists in Denmark', Tourism Economics, Vol 4, No 2, pp 101-130.

Jensen, T., and Wanhill, S. (2002), 'Tourism's taxing times: VAT in Europe and Denmark', Tourism Management, Vol 23, No 1, pp 67-79.

Johansen, S. (1988), 'Statistical analysis of cointegration vectors', Journal of Economic Dynamics and Control, Vol 12, pp 231-254.

Kulendran, N., and Witt, S.F. (2001), 'Cointegration versus least squares regression', Annals of Tourism Research, Vol 28, pp 291-311.

Kulendran, N., and Witt, S.F. (2003), 'Forecasting the demand for international business tourism', Journal of Travel Research, Vol 41, No 3, pp 265-271.

Madsen, B., Jensen-Butler, C., Dam, P.U., and Johnson, H. (2001), The LINE-model, AKF Institute of Local Government Studies, Copenhagen.

Oosterhaven, J., and Van der Knijf, E. (1987), 'On the economic impacts of recreation and tourism: the input-output approach', Built Environment, Vol 13, No 2, pp 96-108.

Smeral, E., and Witt, S.F. (1996), 'Econometric forecasts of tourism demand to 2005', Annals of Tourism Research, Vol 23, pp 891-907.

Song, H., and Witt, S.F. (2000), Tourism Demand Modelling and Forecasting: Modern Econometric Approaches, Pergamon, Oxford.

Song, H., and Witt, S.F. (2003), 'Tourism forecasting: the general-to-specific approach', Journal of Travel Research, Vol 42, No 1, pp 65-74.

Song, H., Romilly, P., and Liu, X. (2000), 'Empirical study of outbound tourism demand in the UK', Applied Economics, Vol 32, pp 611-624.

Song, H., Witt, S.F., and Jensen, T. C. (2003), 'Tourism forecasting: accuracy of alternative econometric models', International Journal of Forecasting, Vol 19, pp 123-141.

Turner, L.W., and Witt, S.F. (2001), 'Forecasting tourism using univariate and multivariate structural time series models', Tourism Economics, Vol 7, No 2, pp 135-147.

Turner, L.W., and Witt, S.F. (2003), Pacific Asia Tourism Forecasts 2003-2005, Pacific Asia Travel Association, Bangkok.

Wanhill, S. (1992), 'Tourism manpower planning: the case of Nepal', in Johnson, P., and Thomas, B., eds, Perspectives on Tourism Policy, Mansell/Cassel, London, pp 87-104.

Wickens, M.R., and Breusch, T.S. (1988), 'Dynamic specification, the long-run and the estimation of transformed regression, models', Economic Journal, Vol 98, pp 189-205.

Witt, S.F., and Witt, C.A. (1992), Modeling and Forecasting Demand in Tourism, Academic Press, London. 
Witt, S.F., and Witt, C.A. (1995), 'Forecasting tourism demand: a review of empirical research', International Journal of Forecasting, Vol 11, pp 447-475.

Witt, S.F., Song, H., and Louvieris, P. (2003), 'Statistical testing in forecasting model selection', Journal of Travel Research, Vol 42, No 2, pp 151-158.

Zhang, J. (2002), 'Tourism impact analysis for Danish regions', Tourism Economics, Vol 8, No 2, pp $165-188$.

Zhou, D., Yanagida, J.F., Chakravorty, U., and Leung, P. (1997), 'Estimating economic impacts from tourism', Annals of Tourism Research, Vol 24, pp 76-89. 